\title{
Manual toothbrushing reinforced with audiovisual instruction versus powered toothbrushing among institutionalized mentally challenged subjects-A randomized cross-over clinical trial
}

\author{
Sachin Goyal ${ }^{1}$, Betsy S. Thomas ${ }^{2}$, Khandige Mahalinga Bhat ${ }^{3}$, G. Subraya Bhat ${ }^{4}$
}

${ }^{1}$ MDS. Senior Lecturer, Department of Periodontics, Bhojia Dental College \& Hospital, Baddi, Himachal Pradesh, India

${ }^{2}$ MDS. Professor, Department of Periodontics, Manipal College of Dental Sciences, Manipal, Karnataka, India

${ }^{3}$ MDS. Professor, Department of Periodontics, Manipal College of Dental Sciences, Manipal, Karnataka, India

${ }^{4}$ MDS. Professor \& Head, Department of Periodontics, Manipal College of Dental Sciences, Manipal, Karnataka, India

Correspondence:

Department of Periodontics,

Bhojia Dental College \& Hospital,

Baddi-17035

Himachal Pradesh,

India

drsachin82@gmail.com

Goyal S, Thomas BS, Bhat KM, Bhat GS. Manual toothbrushing reinforced with audiovisual instruction versus powered toothbrushing among institutionalized mentally challenged subjects-A randomized cross-over clinical trial. Med Oral Patol Oral Cir Bucal. 2011 May 1;16 (3):e359-64. http://www.medicinaoral.com/medoralfree01/v16i3/medoralv16i3p359.pdf

Received: 27/05/2010

Accepted: 14/11/2010

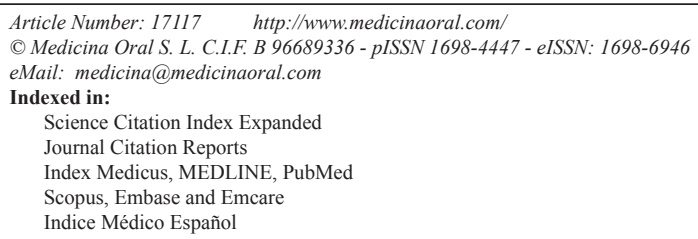

\begin{abstract}
Aim: To assess and compare the effectiveness of Manual toothbrushing reinforced with audiovisual instructions with powered toothbrushing, among the institutionalized mentally challenged individuals under supervision of trained caretakers.

Materials and Methods: A randomized cross over clinical trial of 6 months duration which included 16 subjects consisting of two phases of three months, for each of the 2 groups. In group A subjects were given manual toothbrushes with audio-visual aid followed by the powered toothbrushes \& vice versa for group B. All subjects were instructed by trained care takers. An evaluation of the plaque \& gingival scores was done at the end of $1,2 \& 3$ months for both the groups.

Results: Phase I showed statistically significant decrease in mean plaque scores $(p=0.037)$ but insignificant mean gingival scores $(\mathrm{p}=0.189$ ) in group A at end of 3 months. In phase II, statistically insignificant decrease in mean plaque \& gingival scores were recorded at end of 3 months. In group B a statistically significant decrease in both plaque $(p=0.002) \&$ gingival $(p=0.001)$ was found at end in both phases. Comparison of mean plaque \& gingival scores of manual \& powered toothbrushes at different intervals in both groups were statistically insignificant Conclusion: For mentally challenged individuals, manual toothbrushes reinforced with audio-visual instructions for brushing may be comparable to the use of powered toothbrushes.
\end{abstract}

Key words: Manual toothbrushes, powered toothbrushes, Mentally challenged individuals, Audio-Visual Aids and caretakers. 


\section{Introduction}

Dental plaque is the primary etiological factor in periodontal diseases. The elimination and control of plaque formation helps in the prevention of gingivitis as well as in minimizing the severity of periodontal disease. The adequacy of plaque control depends upon patient's compliance. In physically or mentally challenged person often there arises difficulty in oral hygiene maintenance so the oral hygiene methods may need to be simplified or modified to suit the individual situation.

The health of individuals diagnosed as developmentally disabled or mentally retarded has long been a concern for health professionals. Characteristically, it has been reported that "dental treatment is the greatest unattended health need of the handicapped person (1)." The dental problems of these children are not different than those of the non-handicapped. Inability to maintain proper oral hygiene is one of the primary factors influencing the prevalence of dental disease in handicapped children. The removal of plaque from teeth is a skill that can be mastered only when an individual has the dexterity to manipulate a toothbrush and an understanding of the objectives of this activity (2). Physical inability to adequately clean their teeth and decreased neuromuscular co-ordination in such individuals makes use of manual toothbrushes less effective, so powered tooth brushes have been suggested as an alternative to manual brush for such individuals (3-6)

Also, there seems to be a correlation between the level of oral hygiene and the severity of the mental handicap (7). The poor oral hygiene status described could partly be explained by limitations in personal abilities, but there is quite a strong feeling that parent and caregivers are more interested in general hygiene than in oral hygiene (8). The educators of handicapped children though are well aware of the presence of oral problems such as bleeding gums, halitosis, and the presence of plaque or calculus; do not stress on the implications of these dental problem. Also skill, experience and enthusiasm of the general dental practitioner as being a limiting factor in the delivery of dental care to handicapped people (9).

Historically, health education has addressed the life style and health issues associated with the norm of the population. It has been observed that even severely handicapped children can be instructed in toothbrushing if they are motivated and encouraged $(10,11)$. However, oral hygiene can also be improved significantly by providing intensified daily brushing by dental personnel, development of self-aided workshops, providing effective staff training or by combinations of all these approaches. Also videos have shown to play some role in communicating health messages to target audiences by encouraging viewers to consider their thoughts and actions and to exchange the new ideas with others (12).
So if any efficient means of daily mouth care is provided and made integral component of their personal oral hygiene care, it is likely that the dental professional will help in improving quality of living for these patients.

This particular study aimed to assess and compare the effectiveness of Manual toothbrushing reinforced with audiovisual instructions with powered toothbrushing, among the institutionalized mentally challenged individuals under supervision of trained caretakers. The effectiveness of these interventions in removing plaque and controlling gingivitis was assessed and compared.

\section{Material and Methods}

A randomized cross over clinical trial, operator blinded, which consisted of 2 phases of 3 months duration each. A total of 16 subjects (10 males, 6 females; age group15-25 years) having moderate amount of plaque and gingivitis were studied. All subjects were mild to moderate mentally Handicapped individuals (13) \& residents of Manasa rehabilitation and training centre for Mentally Challenged, Speech \& Hearing Impaired Children, Pamboor, Udupi district, Karnataka India. Informed consent was taken from the school authorities. Approval for the study was granted by institutional board of Manipal University.

\section{Inclusion criteria:}

* Patients with atleast 20 teeth.

* Patients whose parents/ principal will sign on consent form.

Exclusion criteria:

* Patients with true periodontal pockets.

Prior to the commencement of actual study period, caretakers were taught the significance of plaque removal with the help of disclosing agent. They were trained in oral hygiene measures using audio-visual aids such as brushing on models, tooth brushing videos etc. The teeth were professionally cleaned to reduce the plaque scores to baseline.

The subjects and caregivers were randomly assigned by lottery method to one of two groups. In group A, manual toothbrush was assigned for first 3 months followed by powered toothbrush for next three months. The order was reversed in group B - powered toothbrush was used for the first 3 months, followed by manual toothbrush for the next three months.

Both groups were provided with (Oral- $\mathrm{B}^{\circledR}$ : Cross Action Power: 7200 rpm: medium), manual tooth brush (Oral-B ${ }^{\circledR}$ : Cross Action: medium) and dentifrice (Colgate Total ${ }^{\mathbb{}}$ ) during the duration of the study. The clinical scoring procedure was used to assess plaque formation was the plaque index ( Sillness and Loe, 1964) and to assess gingivitis was the Loe and Sillness Gingival index (L-S index, 1963).

The subjects were given 2 weeks to familiarize and adapt to the manual and powered toothbrushes and brushing 
techniques, before commencing the study. At the start of 1st phase, plaque scores were again reduced to baseline. Care takers demonstrated the oral hygiene instructions to the subjects using dental models. Along with this, video recording showing brushing techniques for the manual toothbrushes were shown to the children.

All subjects were told to inform if toothbrush frays or any problem with powered toothbrush in between study period. Subjects were asked to brush twice daily for 2-3 minutes. Oral hygiene instructions were reinforced every 15 th day with appropriate means by caretakers during the study periods.

The subjects were then examined at the end of 1 month, 2 months and 3 months. Each time plaque and gingival status scores were recorded by a single investigator.

At the end of 3 months, cross over was done. The subjects were again given an oral prophylaxis to reduce the plaque scores to baseline, then 2 weeks time for familiarization and adaptation for new brushes and technique. Before commencing the next phase, plaque scores were again reduced to baseline and oral hygiene instructions along with visual aids were shown by the caretakers. Kruskal- Wallis test and Mann Whitney ' $U$ ' tests using the statistical package; SPSS/ version 15 were used for comparisons at a significance level of 0.05

\section{Results}

The subjects improved their plaque control and gingival status during the study period irrespective of toothbrush being used. In case of group-A (manual toothbrush to powered toothbrush), a statistically significant decrease in mean plaque score was found from first to third month $(p=0.037)$. Also there was decrease in mean gingival scores but the decrease was not statistically significant $(\mathrm{p}=0.189)$. When subjects started using powered toothbrush there was decrease in mean plaque $\&$ gingival scores but the decrease was observed to be statistically insignificant after 3 months. $\{(p=0.069)$, $(p=0.111)\}$. But group-B (powered toothbrush to manual toothbrush) showed statistically significant decrease in both plaque and gingival scores at end of both the phases. When the mean plaque and gingival scores of group A \& group B were compared at different intervals there was no statistical significant difference found at any interval during the 6 month study period but powered toothbrush showed slightly better reduction than manual toothbrush. (Table 1-4)

Table 1. Comparison of Mean Plaque Scores of Manual \& Powered Toothbrushes at Different Intervals in Group A.

\begin{tabular}{|c|c|c|c|c|c|c|}
\hline Group & Month & Method & $\mathbf{N}$ & Mean & Std. Deviation & $\mathbf{Z}$ \\
\hline \multirow{6}{*}{$\begin{array}{l}\text { Manual to } \\
\text { Power } \\
\text { (Gp A) }\end{array}$} & \multirow{2}{*}{1} & \multirow{2}{*}{$\begin{array}{l}\text { Manual } \\
\text { Power }\end{array}$} & 8 & 1.1800 & 0.08896 & \multirow{2}{*}{$\begin{array}{c}1.8900 \\
p=0.059\end{array}$} \\
\hline & & & 8 & 1.0650 & 0.13395 & \\
\hline & \multirow{2}{*}{2} & \multirow{2}{*}{$\begin{array}{l}\text { Manual } \\
\text { Power }\end{array}$} & 8 & 1.1350 & 0.17912 & \multirow{2}{*}{$\begin{array}{l}1.88100 \\
p=0.06\end{array}$} \\
\hline & & & 8 & 0.9725 & 0.14008 & \\
\hline & \multirow{2}{*}{3} & \multirow{2}{*}{$\begin{array}{l}\text { Manual } \\
\text { Power }\end{array}$} & 8 & 1.0014 & 0.10976 & \multirow{2}{*}{$\begin{array}{l}2.05900 \\
p=0.059\end{array}$} \\
\hline & & & 8 & 0.9022 & 0.11289 & \\
\hline
\end{tabular}

Table 2. Comparison of Mean Gingival Scores of Manual \& Powered Toothbrushes at Different Intervals in Group A.

\begin{tabular}{|c|c|c|c|c|c|}
\hline Group & Method & $\mathbf{N}$ & Mean & Std. Deviation & $\mathbf{Z}$ \\
\hline \multirow{4}{*}{$\begin{array}{c}\text { Manual to } \\
\text { Power }\end{array}$} & \multirow{2}{*}{$\begin{array}{l}\text { Manual } \\
\text { Power }\end{array}$} & 8 & 1.1788 & 0.32978 & \multirow{2}{*}{$\begin{array}{l}1.37400 \\
p=0.169\end{array}$} \\
\hline & & 8 & 0.9238 & 0.14919 & \\
\hline & \multirow{2}{*}{$\begin{array}{l}\text { Manual } \\
\text { Power }\end{array}$} & 8 & 0.9975 & 0.17425 & \multirow{2}{*}{$\begin{array}{l}1.48100 \\
p=0.139\end{array}$} \\
\hline & & 8 & 0.8513 & 0.10789 & \\
\hline \multirow{2}{*}{$(\mathrm{Gp} \mathrm{A})$} & \multirow{2}{*}{$\begin{array}{c}\text { Manual } \\
\text { Power }\end{array}$} & 8 & 0.9029 & 0.10781 & \multirow{2}{*}{$\begin{array}{l}1.64200 \\
p=0.101\end{array}$} \\
\hline & & 8 & 0.7633 & 0.08441 & \\
\hline
\end{tabular}


Table 3. Comparison of Mean Plaque Scores of Powered \& Manual Toothbrushes at Different Intervals in Group-B.

\begin{tabular}{|c|c|c|c|c|c|c|}
\hline Group & Month & Method & $\mathbf{N}$ & Mean & Std. Deviation & $\mathbf{Z}$ \\
\hline \multirow{6}{*}{$\begin{array}{c}\text { Power to } \\
\text { Manual } \\
\text { (Gp B) }\end{array}$} & \multirow{2}{*}{1} & \multirow{2}{*}{$\begin{array}{l}\text { Power } \\
\text { Manual }\end{array}$} & 8 & 1.1338 & 0.09826 & \multirow{2}{*}{$\begin{array}{l}0.32100 \\
p=0.748\end{array}$} \\
\hline & & & 8 & 1.1463 & 0.13016 & \\
\hline & \multirow{2}{*}{2} & \multirow{2}{*}{$\begin{array}{l}\text { Power } \\
\text { Manual }\end{array}$} & 8 & 0.9925 & 0.06649 & \multirow{2}{*}{$\begin{array}{l}0.42400 \\
p=0.671\end{array}$} \\
\hline & & & 8 & 1.0175 & 0.10236 & \\
\hline & \multirow{2}{*}{3} & \multirow{2}{*}{$\begin{array}{l}\text { Power } \\
\text { Manual }\end{array}$} & 8 & 0.9050 & 0.07672 & \multirow{2}{*}{$\begin{array}{l}1.16800 \\
p=0.243\end{array}$} \\
\hline & & & 8 & 0.9513 & 0.06578 & \\
\hline
\end{tabular}

Table 4. Comparison of Mean Gingival Scores of Powered \& Manual Toothbrushes at Different Intervals in Group-B.

\begin{tabular}{|c|c|c|c|c|c|c|}
\hline Group & Month & Method & $\mathbf{N}$ & Mean & Std. Deviation & $\mathbf{Z}$ \\
\hline \multirow{6}{*}{$\begin{array}{l}\text { Power to } \\
\text { Manual } \\
\text { (Gp B) }\end{array}$} & \multirow{2}{*}{1} & \multirow{2}{*}{$\begin{array}{l}\text { Power } \\
\text { Manual }\end{array}$} & 8 & 1.0613 & 0.07298 & \multirow{2}{*}{$\begin{array}{l}0.27600 \\
P=0.782\end{array}$} \\
\hline & & & 8 & 1.0538 & 0.05829 & \\
\hline & \multirow{2}{*}{2} & \multirow{2}{*}{$\begin{array}{l}\text { Power } \\
\text { Manual }\end{array}$} & 8 & 0.9163 & 0.06823 & \multirow{2}{*}{$\begin{array}{r}0.96200 \\
P=0.336\end{array}$} \\
\hline & & & 8 & 0.9475 & 0.07459 & \\
\hline & \multirow{2}{*}{3} & \multirow{2}{*}{$\begin{array}{l}\text { Power } \\
\text { Manual }\end{array}$} & 8 & 0.8313 & 0.07643 & \multirow{2}{*}{$\begin{array}{l}1.05600 \\
P=0.291\end{array}$} \\
\hline & & & 8 & 0.8863 & 0.07615 & \\
\hline
\end{tabular}

\section{Discussion}

Powered toothbrushes which were introduced in the 1960 's as an alternative to manual toothbrushes are known to be beneficial in special patient situations, as no special dexterity is required in their use $(5,6)$. Maintenance of proper oral hygiene in handicapped individuals is known to be difficult because of psychological and physical limitations and hence powered toothbrush may be better suited for them.

The present cross over study was undertaken to assess and compare the effectiveness of brushing using Manual toothbrush reinforced with audiovisual instructions with, brushing using powered toothbrush, among the institutionalized mentally challenged individuals under supervision of trained caretakers. The use of both manual and powered toothbrushes by the same subjects in both groups, albeit at different time periods, helped to minimize possible variations, which may occur because of inter individual differences like age, habits, manual dexterity, plaque levels and compliance (14).

Although the plaque scores were brought down to baseline at the beginning of the study, a moderate amount of clinically appreciable plaque was observed at the end of the one month in group A with manual toothbrush. Significant decrease in the mean plaque score was observed at the end of 3rd clinical assessment thus showing an increase in compliance with time.

In case of group A, slight but statistically insignificant reduction in gingival scores was recorded from 1st to 3rd month. The statistically insignificant reduction in gingival scores, though plaque scores have reduced significantly may be because of inter-subject variation in the pathogenicity of plaque and an exaggerated effect of plaque reduction which resulted from volunteers paying particular attention to cleaning the subjects teeth on the days of clinical examination (15-17).

The so called Hawthorne effect \{Heasman et al. (14), Ainamo et al. (17)\} which results from a change in behaviour of a subject, who anticipates involvement in a clinical study, can be a confounding source of variability in crossover trials, giving rise to different conditions between the first $\&$ succeeding experimental periods. In our study, the anticipation of an upcoming appointment may have prompted the participants to perform better oral hygiene during that period of time.

The constant reinforcement of oral hygiene instructions given to the subjects during the previous three months of manual toothbrush use and ease of using powered toothbrush, might have contributed in better plaque control which resulted in non significant reduction in plaque and gingival scores following use of powered toothbrush.

But in group B, a significant improvement in plaque control \& gingival status was observed with time for both the devices and when the plaque and gingival scores for the manual and powered toothbrush in both 
the groups [Group A (Table 1, 2) \& Group B (Table 3, 4)] were compared, both the brushes showed a comparable results. This correlates well with the previous reports of Paul W et al. (18), Bratel et al. (19).

The marginal improvement in mean plaque and gingival scores observed in present study with powered toothbrush could be because of ease of using the powered toothbrush and the smaller size of the brush head (20-23). These toothbrushes require lesser effort on the part of the patient by virtue of their automated action. Their machined rotatory bristles offers the necessary movement for removal of plaque, an action similar to that performed by the patient's hand in case of a manual toothbrush, only without the patient's personal physical effort.

Also, the powered toothbrush plays a major role in enhancing patient compliance and motivation. It has been seen that powered toothbrushes also have "novelty effect" that helps to increase the compliance. Better plaque removal from interproximal sites may have contributed to the improvement in gingival condition (16, 24-26). Moreover, the gingival massage provided by the powered toothbrush seems to play a significant role in improving gingival condition. Likewise, Glickman stated that the improved gingival condition observed subsequent to tooth brushing and other oral hygiene procedures might be because of a concurrent massage effect associated with the cleansing action.

Though manual toothbrushes require additional effort and manual dexterity in maintaining good oral hygiene, adequate instructions and practice can bring about satisfactory results, which may be comparable with the powered toothbrush which has been observed in our study. Furthermore, verbal instructions are generally less comprehensible to mentally challenged individuals, and their understanding of the method of toothbrushing, as well as their dexterity in using a manual toothbrush may be limited. In the present trial, demonstration of the manual oral hygiene technique by means of a visual aid, such as the recorded video can be considered to be more effective in teaching these individuals, and easier for them to remember and recall at a later date.

The regular visits and the constant reinforcement that the inmates received every 15 days through the caretakers may be a major reason for better compliance, which reflected in their increased interest to maintain good oral hygiene. The constant reinforcement was done because the mentally challenged patients often have a shortterm memory deficit and thus the dental professionals/care takers/parents should reinstruct more often at subsequent appointments than one would expect with a child or adult with normal intelligence. This could have helped in achieving comparable scores with two different methods of brushing. Bratel et al. (19) had reported that the reduced positive effect over time in maintaining oral hygiene may indicate that the reinstruction is more important with a prophylactic program, rather than to operate with different toothbrushes.

It has been suggested that in mentally challenged individuals a feeling of insecurity is seen due to the attitude of general population towards them. The current study provided an opportunity to make some observations of the psychosocial aspects prevailing in such individuals. The feeling of being neglected and a sense of 'unwantedness' was reflected in the behaviour of most of the subjects in the beginning of the study but as the study progressed, the compassion shown to them helped in achieving better cooperation.

In developing countries, the average socio-economic status of institutes for the handicapped funded by the government or by non-government organizations may not permit them to purchase powered toothbrushes for all the inmates. Also, the lack of awareness regarding the availability of powered toothbrushes, may limit their use. In this scenario, the use of manual toothbrushes in adjunct with audio-visual instructions and constant reinforcement of oral hygiene measures may prove to be a viable, cheaper and readily available alternative for ensuring optimum periodontal health.

\section{Conclusions}

In conclusion, our investigation documented the following:

$>$ For mentally challenged individuals, manual toothbrushes reinforced with video instructions for brushing techniques may be comparable to the use of powered toothbrushes in a similar setup.

$>$ The regular visits and the constant reinforcement that the inmates received through the caretakers may be a major reason for better compliance to improve the oral hygiene.

\section{References}

References with links to Crossref - DOI

1. Dierdre P. Dental care for the handicapped. Br Dent J 198120 : 267-270.

2. Pinkham JR. Oral hygiene in children: relationship to age and brushing time. J Prev Dent. 1975;2:28-31.

3. Full CA, Kerber PE, Boender P, Schneberger N. Oral health maintenance of the institutionalized handicapped child. J Am Dent Assoc. 1977;94:111-3

4. Bozkurt FY, Fentoglu O, Yetkin Z. The comparison of various oral hygiene strategies in neuromuscularly disabled individuals. J Contemp Dent Pract. 2004;5:23-31.

5. Hoover JN, Singer D. Toothbrushes: manual and electric. J Can Dent Assoc. 1994;60:880-4.

6. Ashley P. Toothbrushing: why, when and how? Dent Update. 2001;28:36-40.

7. Shaw L, Maclaurin ET, Foster TD. Dental study of handicapped children attending special schools in Birmingham, UK. Community Dent Oral Epidemiol. 1986;14:24-7.

8. Mann J, Wolnerman JS, Lavie G, Carlin Y, Garfunkel AA. Periodontal treatment needs and oral hygiene for institutionalized individuals with handicapping conditions. Spec Care Dentist. 1984;4:173-6. 
9. Pool D. Dental care for the handicapped. Br Dent J. 1981;151:267-

70.

10. Holland TJ, O'Mullane DM. Dental treatment needs in three institutions for the handicapped. Community Dent Oral Epidemiol. 1986;14:73-5.

11. Nicolaci AB, Tesini DA. Improvement in the oral hygiene of institutionalized mentally retarded individuals through training of direct care staff: a longitudinal study. Spec Care Dentist. 1982;2:217-21.

12. Trulsson U, Klingberg G. Living with a child with a severe orofacial handicap: experiences from the perspectives of parents. Eur J Oral Sci. 2003;111:19-25.

13. Dinesh RB, Arnitha HM, Munshi AK. Malocclusion and orthodontic treatment need of handicapped individuals in South Canara, India. Int Dent J. 2003;53:13-8.

14. Heasman PA, McCracken GI. Powered toothbrushes: a review of clinical trials. J Clin Periodontol. 1999;26:407-20.

15. Spindel LM, Chauncey HH, Person P. Plaque reduction unaccompanied by gingivitis reduction. J Periodontol. 1986;57:551-4.

16. Stoltze K, Bay L. Comparison of a manual and a new electric toothbrush for controlling plaque and gingivitis. J Clin Periodontol. 1994;21:86-90.

17. Ainamo J, Xie Q, Ainamo A, Kallio P. Assessment of the effect of an oscillating/rotating electric toothbrush on oral health. A 12-month longitudinal study. J Clin Periodontol. 1997;24:28-33.

18. Warren PR, Ray TS, Cugini M, Chater BV. A practice-based study of a power toothbrush: assessment of effectiveness and acceptance. J Am Dent Assoc. 2000;131:389-94.

19. Bratel J, Berggren U. Long-term oral effects of manual or electric toothbrushes used by mentally handicapped adults. Clin Prev Dent. 1991;13:5-7.

20. Forrest JL, Miller SA. Manual versus powered toothbrushes: a summary of the Cochrane Oral Health Group's Systematic Review. Part II. J Dent Hyg. 2004;78:349-54.

21. Robinson PG, Deacon SA, Deery C, Heanue M, Walmsley AD, Worthington $\mathrm{HV}$, et al. Manual versus powered toothbrushing for oral health. Cochrane Database Syst Rev. 2005;2:CD002281.

22. Davies RM. Manual versus powered toothbrushes: what is the evidence? Dent Update. 2006;33:159-62.

23. Khocht A, Spindel L, Person P. A comparative clinical study of the safety and efficacy of three toothbrushes. J Periodontol. 1992;63:603-10.

24. Howorko N, Gutek M, Naidoo S, Hoover JN. Effectiveness of an electric toothbrush on plaque removal in periodontal patients. Am J Dent. 1993;6:49-51.

25. Barnes CM, Weatherford TW 3rd, Menaker L. A comparison of the Braun Oral-B Plaque Remover (D5) electric and a manual toothbrush in affecting gingivitis. J Clin Dent. 1993;4:48-51.

26. Van der Weijden GA, Timmerman MF, Nijboer A, Lie MA, Van der Velden U. A comparative study of electric toothbrushes for the effectiveness of plaque removal in relation to toothbrushing duration. Timerstudy. J Clin Periodontol. 1993;20:476-81. 